\title{
Proposal of the Financial Plan for the Implementation of the Educational Activities Supported by the Contemporary Technologies in High-Education Institution
}

\author{
Andrija Nenadic \\ University of Split, Split, Croatia \\ Aleksandra Krajnovic, Drazen Jasic \\ University of Zadar, Zadar, Croatia
}

\begin{abstract}
The paper deals with the introduction of the e-learning system into higher education institutions. Numerous advantages of the e-learning system have been evidenced and this paper's goal is to discuss the economic justification of the implementation of such a system, in particular due to the fact that financing is one of the most common obstacles to implementing e-learning systems in higher education. The paper presents a potential model for financing the system and the cost analysis in line with the system's implementation dynamics. Furthermore, the authors point out to potential risks that may occur when introducing an e-learning system and a risk management plan. The third part of the paper deals with important aspects of the monitoring and quality control of the e-learning system. The authors have used the analytical method combined with their own empirical experience in educating seafarers at the Universities of Split and Zadar in the Republic of Croatia. The results produced by the research prove that, prior to introducing e-learning and similar systems supported by contemporary technologies into higher education institutions, it is necessary to make, using an analytic approach, an overall plan of financing the system and the budget featuring a detailed overview of anticipated costs and the dynamics of the system implementation. Moreover, prior to implement the system, it is necessary to make an analysis of potential risks in order to reduce them to a minimum during and after the implementation. Since the risk analysis is logically related to the issue of the system's monitoring and quality control, the authors propose an introduction of a system of the e-learning quality evaluation and a definition of specific indicators — quality standards, aiming at a methodical follow-up of the system's efficiency, successfulness, and quality. The authors conclude that the key factors of the e-learning system introduction include financial planning and analysis, well-defined educational goals, follow-up of the realisation of the set goals through monitoring and quality control systems, and effective risk management. If all the above mentioned essential factors are taken into consideration, there will be no obstacle to implement e-learning and similar systems supported by contemporary technologies into all higher education institutions, in view of the numerous advantages of these systems and their benefits to the modern globalised society that aspires to become the knowledge society.
\end{abstract}

Keywords: financial planning in education systems, high education systems, e-learning, risk analysis in educational institutions

Andrija Nenadic, Ph.D., Assistant Professor, Head of the Department Library, University of Split. Aleksandra Krajnovic, Ph.D., Assistant Professor, Department of Economics, University of Zadar. Drazen Jasic, Ph.D., Assistant Professor, Department of Maritime Studies, University of Zadar.

Correspondence concerning this article should be addressed to Aleksandra Krajnovic, Ph.D., University of Zadar, Department of Economics, Splitska 1, 23000 Zadar, Croatia. E-mail: akrajnov@unizd.hr. 


\section{Introduction}

Undoubtedly, the historical development of education can confirm that teaching supported by information and telecommunication technologies can, if intelligently carried out, have a number of advantages over traditional teaching in the classroom. This is particularly evident in the application of the latest technology that allows us to come close to the ideal of teaching during which the teacher and the student do not have to be in the same place at the same time. If we add the possible savings, it becomes clear why, since the early 20th century, we have experimented with every new technology potentially interesting to the educational systems.

With the questions of efficiency of certain systems of distance education and their quality, one of the decisive factors in choosing the most suitable system is the question of resources which are necessary for their functioning. The most important items in the cost of distance education systems according to Bates (2004) ${ }^{1}$ are:

- costs of preparation and production of teaching materials;

- distribution costs of course materials to distant students;

- system maintenance costs.

\section{The Costs of Studying}

In analyzing the costs of introducing new technologies, among other things, it is important to point out the costs of technological infrastructure and the costs of applying new technologies to administrative and academic needs. Until recently, the investments were made primarily because of the administrative needs, not the academic needs. University Information Systems were originally developed for the purpose of registration and for keeping records of students, for the account-keeping, administration and human resources departments. Even the communication systems, such as telephone and electronic mail, were introduced primarily for the management and administration needs.

What happens is that the support for educational technology is not sufficiently funded because of the lack of understanding of its importance, or because the priority is given to some other areas, such as research.

Therefore, it is necessary to clarify the characteristics of the costs of technology for the needs of education and what influence it would make on the students first, and then consider a strategy of funding, claims by Bates $(2004)^{2}$.

\section{The Calculation of the Costs of Education Supported by the Contemporary Technologies}

Calculating the costs of education supported by the instructional technologies is a very complex issue, claimed by Bates (2004) ${ }^{3}$ and Rumble (1997) ${ }^{4}$. The authors separate the production costs and variable costs. According to them, these production costs do not change with the number of students while change with the variable costs.

One of the elements of production cost is the cost of the production of teaching materials. After the CD-ROM was designed and built, its costs are given regardless of the number of students who will then use it. However, the cost of distribution is variable: if the number of students gets bigger, it is necessary to make more

\footnotetext{
${ }^{1}$ Bates, A. W. (2004). Upravljanje tehnološkim promjenama: Strategije za voditelje visokih učilišta. Zagreb: CARNet/Benja.

2 Same, p. 93.

3 Same, p. 93.

${ }^{4}$ Rumble, G. (1997). The costs and economics of open and distance learning. London: Kogan Page.
} 
copies, thereby increasing the cost of duplication and distribution. There is a difference between the costs of education supported by the new technologies and the education that takes place within a classroom.

In the traditional model of higher education, if the number of students grew, the expenses grew too, or the quality of teaching would decrease. In other words, according to Bates, if we want to maintain a constant ratio between the number of teachers and the number of students, it is required to increase the number of teachers. If you cannot hire new teachers, the number of students for a certain course increases, there is less interaction with the teacher, the quality of the course decreases.

The structure of the costs for education supported by new technologies is significantly different. The courses to be held with the support of these technologies are very expensive at the beginning, but once they are set, they can be used by many students with a very small increase in cost. According to Bates, their production costs are high, but variable costs are low compared with the education that takes place in the classroom.

The original multi-media materials, such as CD-ROM which is entirely made by the teacher or a project team, have a higher "initial” or production cost than the teaching in the classroom does, but after the materials were produced, the only additional cost is the costs of copying and distribution.

High quality multimedia materials can contain a lot of information and simultaneously allow interaction and feedback that otherwise would be provided by the teacher. This allows the teachers to focus only on those situations where direct personal contact is most needed. Computers are not smart enough to anticipate all the questions, misunderstandings, and more importantly, original and creative contributions of students. Therefore, it is still necessary to enable not only the interaction between students and teachers, but also the interaction among students. In traditional ways of teaching, this interaction takes place in small seminar groups. This form of interaction in the education supported by contemporary technologies is the on-line debates/forums, such as teleconferencing. Therefore, it is important to take into account not only the costs of the production of multimedia teaching materials, but also the cost of on-line debates and teaching.

\section{Costs Arrangement}

Establishing the costs for realization could be divided into several basic points such as:

- overhead costs;

- costs for maintenance of the programs of on-line classes;

- student costs according to classic and on-line mode of teaching.

When it comes to determining the overhead costs there is a difficulty in creating a budget for the use of the technology (see Figure 1). Overhead costs are various expenses that any organization has to settle, according to Bates, those costs are general and it is difficult to assign them to a specific activity. For example, the buildings in which teaching takes place in the classroom fall into that type of cost. There are two types of costs of the building: construction costs and maintenance costs (see Figures 1 and 2). Construction costs are usually high, these are one-time investments in the premises and the equipment. Construction and interior design of the building are clear examples of capital costs. Costs of the cold drive, such as annual costs for heating, cleaning, building maintenance, and utility costs are overhead costs and they are repeated every year, according to Bates $(2004)^{5}$ (see Figure 2).

\footnotetext{
${ }^{5}$ Compare with Bates A.W. (Tony), pp. 111-130.
} 


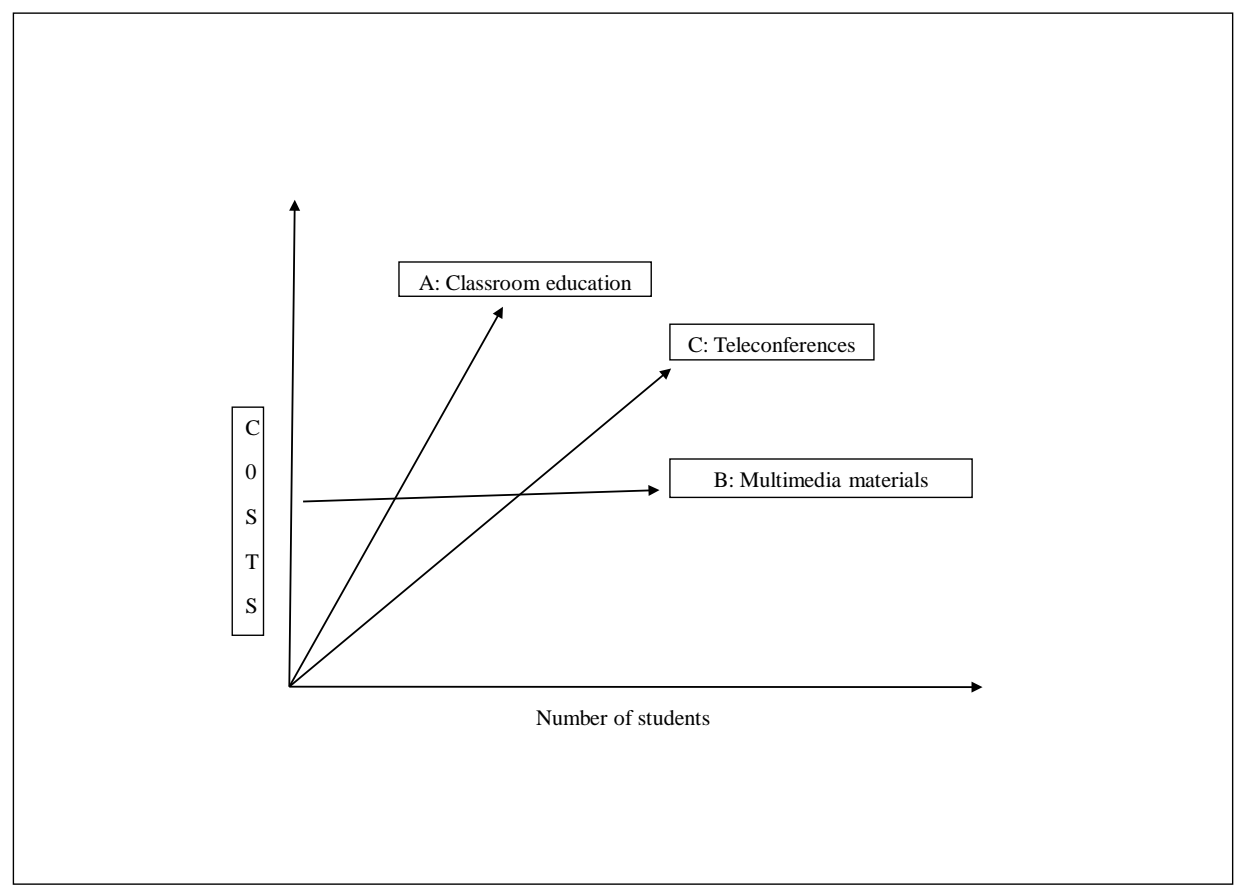

Figure 1. Teleconferencing costs. Source: Bates (2004).

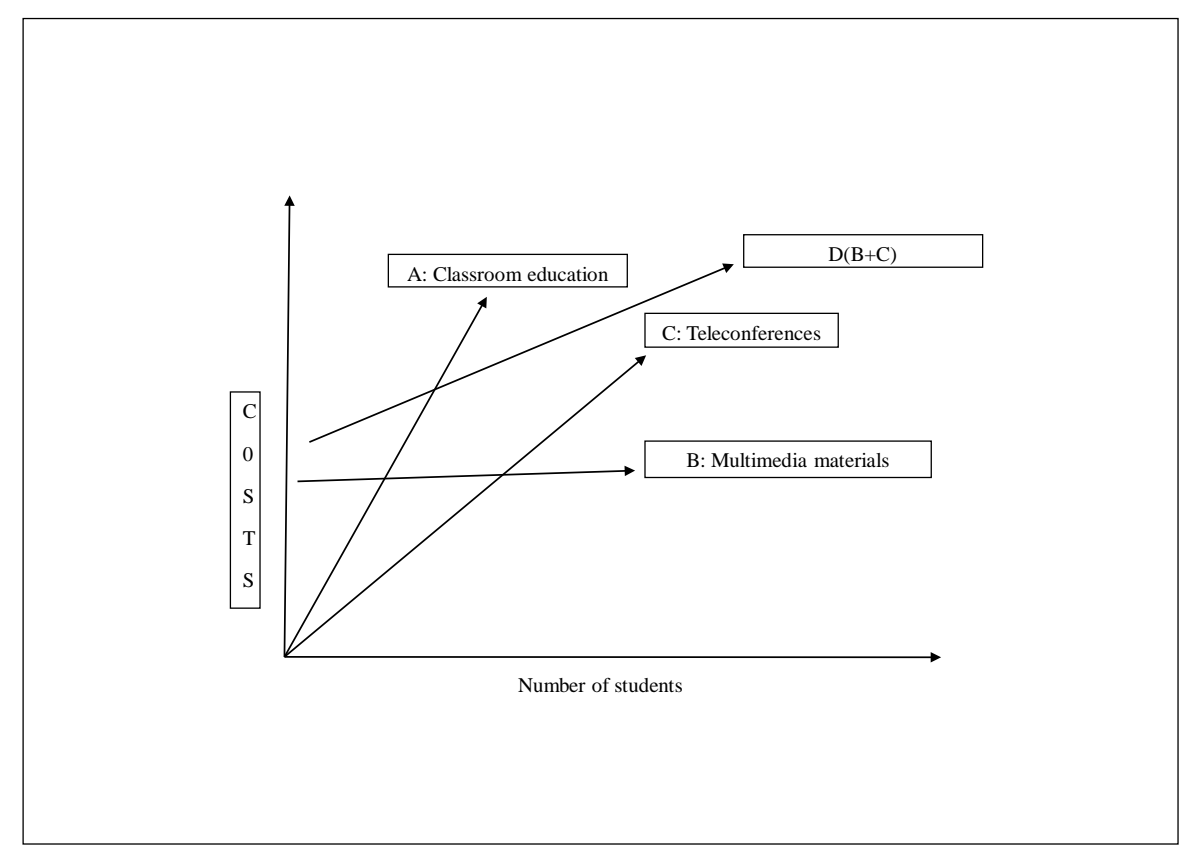

Figure 2. Ratio of costs of teaching in the classroom and teaching with multimedia and teleconferencing. Source: Bates (2004).

Besides the costs of the buildings and infrastructures, the overhead costs also include the staff salaries. The usual way of booking these costs, such as salaries, benefits, travel expenses, etc., is to distribute them equally 
between all of the courses. According to Bates, there are other overhead costs, such as purchasing computers and providing technical support, phone costs, heating, lighting and so on (see Figure 2).

\section{Determining the Costs of the Program Maintenance}

Websites are made by using special servers software that uses Hyper Text Transfer Protocol (HTTP). The most popular softwares for servers run on UNIX or Windows NT computers.

Operation and maintenance of web servers must be entrusted with the person who is trained in programming. In addition, according to Bates, anyone who teaches several courses supported by the modern technologies will also have to have at their disposal a backup system that can take over the work if the server breaks down or needs servicing, in order to provide services to students during the period of 24 hours. One can choose between several different approaches for the development of on-line courses. A common approach is to use HTML to "manually" set up web pages. Another approach is to use the integrated web application (like WebCT), which the author can use in all the phases of designing and managing online content. ${ }^{6}$

The institution that offers online education programs mostly uses the simplest and the most reliable system, because by doing so, it avoids the high costs of technical support and training of the students.

The costs of technical support for students can be reduced if the students themselves provide the Internet access, whether it is approached through a university network or any other network system. ${ }^{7}$

\section{Budget Planning for the Expenditures Required for the Design and Implementation of Teaching by Introducing E-learning System in Higher Education Institution}

In order to even start the process of implementation of e-learning in any institution, it is necessary to make strategic plans and objectives that we want to accomplish. The financial plan of introducing the e-learning should certainly be one of the strategic plans to take into account. One of the most unfavorable situations that could happen, according to Bates (2004) ${ }^{8}$ for the administration of the faculty is to invest into the infrastructure (buying all the necessary equipment, computers, servers etc.) but not to know what to do with all that equipment. For this and other reasons, along with all the other strategies, the financial strategy of introducing e-learning is certainly an important one.

In order to avoid mistakes in implementing new technologies in teaching process, Table 1 gives a proposed financial plan which concentrates on several main items.

Table 1 shows that the activities are divided into four main sections: presentation, technology, personnel, and materials. Each of the proposed activity contains the time, quantity, and cost proposal.

The budget, which is suggested here, amounts to Kn 1,500,000.00.

- Fifteen percent of the total amount $(225,000.00 \mathrm{kn})$ is proposed for operating costs (overhead costs) of the Faculty: Student Administration Office operations, legal, library and general affairs;

- Of the total amount, the $20 \%$ (HRK 300,000.00) is proposed for the teachers' fees and education;

- Twenty-five percent of the total amount $(375,000.00 \mathrm{kn})$ is proposed for travel expenses and per diems;

- Forty percent of the total amount $(600,000.00 \mathrm{GBP})$ is recommended for equipment, maintenance, servicing, the cost of teaching aids, paying to use a database, etc..

\footnotetext{
6 Compare Bates 2004, p. 93.

7 Same, p. 93.

${ }^{8}$ Compare with Bates A. W. (Tony), pp. 111-130.
} 


\section{Potential Risks and the Plan to Overcome the Risks}

The introduction of ICT is a complicated process that has been tried in Croatia by many companies, and to some extent, by the educational systems. It is useful to know that this process will develop in every place by the typical pattern of embracing innovation and resistance to change that has been perceived in the 1960s in the 20th century, and that the educational systems will suffer due to some specific problems (lack of familiarity with the technology, lack of technical staff, lack of money etc.).

Table 1

An Overview of the Financial and Other Resources Within the Strategic Plan, Including the Number of Part-Time Teachers, Materials, Costs, Equipment, and Administrative Expenses

\begin{tabular}{|c|c|c|c|}
\hline Activities & Quantity & Time & Price/kn \\
\hline \multicolumn{4}{|l|}{ Presentation } \\
\hline Presentation of the course that introduces e-learning & 2 & 5th and 9th in Nov. & 100,000 \\
\hline Transition workshops & 3 & 9th Oct.-9th Nov. & 50,000 \\
\hline \multicolumn{4}{|l|}{ Technique } \\
\hline Upgrading of computer classrooms & 60 computers & 6th Nov. & 300,000 \\
\hline $\begin{array}{l}\text { Equipping laboratories with audio and video equipment, hardware and } \\
\text { software equipment, in order to record the exercises and uploading them } \\
\text { on the web }\end{array}$ & & 2011 & 100,000 \\
\hline Laptops for teachers & 10 & 8th Nov. & 90,000 \\
\hline \multicolumn{4}{|l|}{ Careers } \\
\hline Education teacher-ELA + Design Course - 1 student & $11 \times 300$ hours & 2010 and 2011 & 165,000 \\
\hline Teacher's salaries & 10 & 2010/2011/2012 & 100,000 \\
\hline Technical support for the teachers and students & 1 & 2010/2011/2012 & 40,000 \\
\hline Administration costs & 1 & 2010/2011/2012 & 60,000 \\
\hline \multicolumn{4}{|l|}{ Materials } \\
\hline Web design & 1 & 6th Nov. & 20,000 \\
\hline Installing LMS & 1 & 7/8/9/ in Nov. & 50,000 \\
\hline Creating content and materials for 10 courses and software support & 10 & 9th Sep.-5 Nov. & 400,000 \\
\hline Creating content for progress evaluation & 10 & $3 / 4$ in Nov. & 25,000 \\
\hline Total & & & $1,500,000$ \\
\hline
\end{tabular}

Note. Source: Authors ${ }^{9}$.

In order for ICT to be accepted and approved by a majority of employees and students in educational systems, a lot of changes need to happen within the systems themselves. Technological innovations, such as e-learning, will only start to be realized in the organizations that will assist in various ways to help the change take place. This means that the introduction of e-learning will be planned and conducted by the management of the system or of the institution.

The personnel must be able to improve their education skills which are necessary for working with the new technologies and this can only be accomplished through continuous education. In order to successfully work toward this idea, by using small steps, it will be necessary to organize working teams and to work by the projects (Tingle, 2004). ${ }^{10}$

The risk analysis is being conducted in order to assess the risk, and it helps in deciding which activities

\footnotetext{
${ }^{9}$ Made by the instructions and assignments of ELA courses in 2007 in which the author of this article took part in. Retrieved from http://www.carnet.hr/ela.

10 Tingle (2004). Retrieved from http://www.carnet.hr/casopis/24.
} 
can be used to minimize the impact on the plan. Loss of confidence by the business partners and poor image on the market represent the extremes that should be avoided through a plan to overcome the risks.

For the projects of introducing new e-learning programs to be successful, their holders and managers should be familiar with the theoretical foundations of the project work, and certainly the most important segment of the project work is the initiation and project planning. To implement the plan, according to Bates $(2004)^{11}$, we need the individuals who have the power to implement certain strategies or procedures that will direct the institution to its goals and its vision.

\section{The Risk of Human Resources}

For the purpose of acquiring our teaching staff to use new technologies, new ways of teaching and learning and getting acquainted with them, it is necessary to encourage the use of free resources that are available to us. CARNet has valuable experience in the design and implementation of online classes, such as: projects that encourage the application of ICT in education, and education projects in the field of ICT and those who provide support and assistance to developing e-learning and create a training ground for the exchange of information. CARNet offers different services to the teaching and scientific staff: online courses (courses on how to search and browse the internet, ECDL online courses), online textbooks, and e-learning academy. Half-day seminars for teachers who are new to online teaching cover issues related to the role of teachers in supporting students and the help in managing the courses, the details of the effective management of online discussions and communications and other aspects of teaching. The staff will yield better performance if they know that they will receive recognition for their willingness to engage in innovative online education activities, and that their efforts will ensure a secure job, salary increases and other tangible benefits, according to Caplan (2005). ${ }^{12}$

To enable and facilitate the use of certain technologies, institutions must provide students with various forms of support such as online applications and enrollment for distant students, technical support, technical assistance in selecting programs, help in mastering the content, assistance in organizing learning activities, access to literature and other forms depending on the structure of the participants (Tingle, 2004). ${ }^{13}$

\section{Procedure Risk}

The procedure risks are reflected in unreliability on the internal control systems, organization, and fraud. In order to avoid the risks in this area, it is necessary to describe the goals in measurable terms and plan and monitor the overseeing that are, checking through a system of internal control. The results of monitoring should be made available to all members of the project and thus prevent the repetition of errors and fraud.

\section{Monitoring and Control}

To ensure the quality of the implementation of the development of e-learning at the educational institution, it is necessary to apply an independent evaluation system that allows assessment of the extent to which e-learning supports the achievement of learning goals (primarily according to the user) and raises the quality of education (see Figure 3). Such an evaluation system would offer information about the benefits of investing in the system, especially in terms of unanticipated or unseen costs of implementation to back office systems, staff,

\footnotetext{
11 Compare Bates (2004), pp. 111-130.

12 According to Caplan (2005). Retrieved from http://www.carnet.hr/casopis/40.

13 Compare Tingle (2004). Retrieved from http://www.carnet.hr/casopis/24.
} 
and infrastructure. Within this framework, it is important to provide good control mechanisms and specific indicators for monitoring the successfulness of achieving the objectives in the areas which include teaching and learning (see Figure 3). Methods of monitoring include: survey of students at different stages of education, data collection, and quantitative data analysis, evaluation at the end of each course and professor self-evaluation (see Figure 3). Type, scope and framework of evaluation must be independent and structured to deliver results that will help in improving the system, or lead to an informed decision whether to disregard the certain steps of the system or alter the system with the help of new resources (see Figure 3).

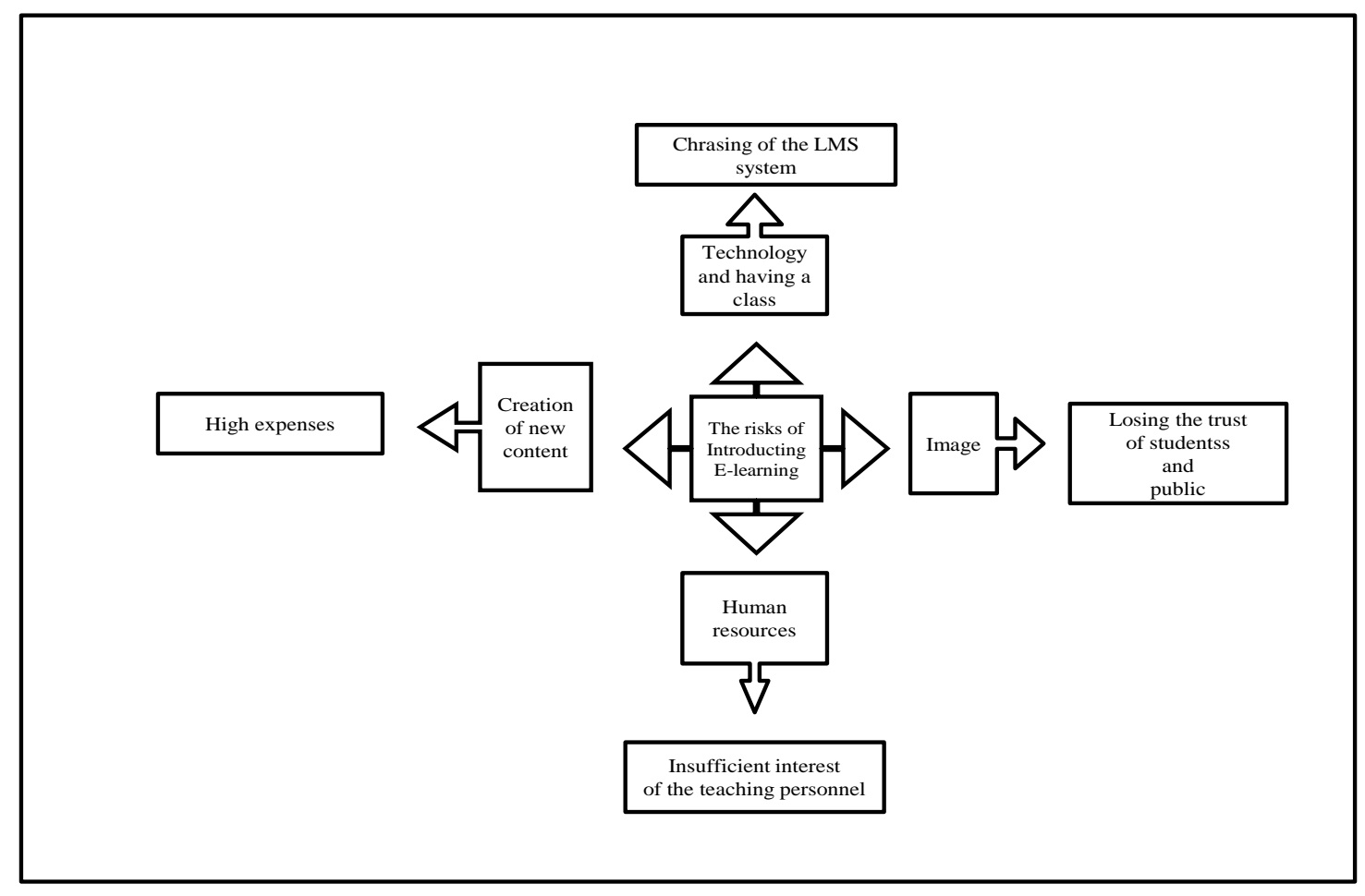

Figure 3. Possible risks in introducing e-learning. Source: Authors. ${ }^{14}$

Particular attention should be given to technical problems, their frequency and speed of their removal. The proposed project of designing the educational system by using the e-learning was at the beginning of the academic year 2010-2011. It is possible to plan and achieve all its objectives and to implement e-learning within some professional studies.

Many years of positive experiences in organizing similar studies within the institutions with a very positive reputation gives us the right to expect positive results in implementing e-learning in our educational institution. Good communication with prospective students, clear marketing strategy as well as academic activities tailored to the socio-economic needs of the participants would allow the improvement of educational quality and increase the number of students who would enroll in the institution.

The possibility of participation in the international knowledge market, taking leading positions in the country and the region in the field of maritime affairs and the involvement of foreign teachers would certainly

\footnotetext{
14 Made by the instructions and assignments of ELA courses in 2007, in which the author of this article took part in. Retrieved from http://www.carnet.hr/ela.
} 
contribute to a better international reputation of higher education institutions which enable it to compete in their field.

It is well known that the design of e-learning content and implementation of online teaching requires significant fundings so it would be necessary to ensure the fundings from multiple sources. In addition to the Ministry of Science, which would assist in introducing new educational system, a certain role, including the financial support, should be given to the Ministry of Maritime Affairs. We should not forget the shipping companies that would benefit from introduction new, flexible learning programs for their employees - mariners. If we come up with a good marketing presentation, the shipping companies would certainly help the educational institution with considerable money investments.

\section{Conclusion Remarks}

The goals of these and other plans are to increase the quality of education of students with maximum support and use of the available media and information and the encouragement for the teachers to apply the technology available to them. The specific objective for the profession of the seafarer is to prepare students for lifelong education and training. In this sense, it is necessary to keep in mind the needs of the students depending on their qualities and abilities. It is important to enable them to have an access to materials through a variety of formats (text, video, on-line WebCT courses etc.).

To achieve these goals, it is important to consider the financial funding. The primary precondition is to make a good and well worked-out financial plan at the institution level, the institution that wants to introduce modern technologies to its educational system. The carefully planned financial plan, with initial investments, in its further implementation can greatly contribute to reducing costs for both the institution and the students.

\section{References}

Ally, M. (2005). Osnovne obrazovne teorije online učenja. Retrieved from http://www.carnet.hr/casopis/38/clanci/3 Bates, A. W. (2004). Upravljanje tehnološkim promjenama: Strategije za voditelje visokih učilišta. Zagreb: CARNet/Benja. Belfier, K. (2004). Model 5C_Evaluacija na razini aktivnosti. Retrieved from http://www.carnet.hr/casopis/38/clanci/3 Caplan, D. (2005). Razvoj online kolegija. Retrieved from http://www.carnet.hr/casopis/40

Car, A., Ćorić, G., ... Luković, Z. (n.d.). Printed material Prijelazna radionica (E-learning academy). Retrieved from http://elacd.carnet.hr/index.php/Projektni_plan_2_grupa

Rumble, G. (1997). The costs and economics of open and distance learning. London: Kogan Page.

Teaching materials CARNet E-learning Academy (6th course: Planning at the program level). (n.d.). Retrieved from http://www.carnet.hr/ela/programi

Tingle, J. (2004). E-learning. Retrieved from http://www.carnet.hr/casopis/24 